\title{
Uso de vacinas no controle da coccidiose aviária
}

\section{The use of vaccines for chicken coccidiosis control}

\author{
Guilherme Felippelli Martins ${ }^{1}$; Alexey Leon Gomel Bogado ${ }^{1}$; \\ José da Silva Guimarães Junior ${ }^{2}$; João Luis Garcia ${ }^{2 *}$
}

\begin{abstract}
Resumo
O gênero Eimeria pertencente ao subfilo Apicomplexa, Família Eimeriidae com sete espécies reconhecidas infectando galinhas: E.acervulina, E.maxima, E.tenella, E.brunetti, E.necatrix, E.mitis e E.praecox. Trata-se de um parasito intracelular obrigatório que causa doença pela destruição de células do epitélio intestinal em seu processo de replicação. $\mathrm{O}$ uso indiscriminado de anticoccídicos tem resultado na seleção de cepas resistentes a drogas, as quais reduzem a eficácia de vários anticoccídicos usados atualmente no controle dessa parasitose. Como em muitos países a legislação pró́be o uso destes produtos continuamente até o abate, períodos de retirada têm sido exigidos, o que aumenta o risco de infecção no final do período de crescimento. Desta forma, as vacinas são fundamentais como ferramenta de controle destes parasitas. Existem atualmente diversos tipos de vacinas, porém somente vacinas vivas e atenuadas são comercializadas para o controle da coccidiose aviária, com exceção da vacina recombinante CoxAbic ${ }^{\circledR}$. Apesar disso, o seu uso ainda é discreto frente ao uso de anticoccidianos, possivelmente devido a sua menor eficácia e maior custo. Desta forma, é importante ressaltar que o controle da coccidiose aviária é extremamente complexo, e que, novos estudos devem ser estimulados para o desenvolvimento de métodos eficazes, entre eles o uso de vacinas, para a produção de carne de frango livre de medicamentos.
\end{abstract}

Palavras-chave: Eimeriose aviária, vacinas, controle, imunógenos

\begin{abstract}
The genus Eimeria belonging to the Subphylum Apicomplexa, Family Eimeriidae, have seven recognized species infecting chickens: E.acervulina, E. maxima, E.tenella, E.brunetti, E.necatrix, E.mitis and E.praecox. It's an obligate intracellular parasite that causes disease by the destruction of intestinal epithelial cells in the replication process. The indiscriminate use of anticoccidial drugs has resulted in the selection of drug-resistant strains, which reduce de effectiveness of various anticoccidial drugs used currently in control of the disease. As in many countries legislation prohibits the use of thes products continuously until slaughter withdrawal periods have been required, which increases the risk of infection at the end of the growing season. Thus, vaccines are essential as a tool for controlling these parasites. There are several types of vaccines, but only attenuated live vaccines are marketed for the

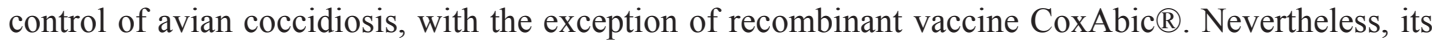
use is still mild compared to the use of anticoccidial drugs, possibly due to its lower cost and greater effectiveness. Thus, it is important that control of avian coccidiosis is extremely complex, and that further studies should be encouraged to develop effective methods, including the use of vaccines for the production of chicken meat free of medication.
\end{abstract}

Key words: Avian eimeriosis, vaccines, control, immunogens

\footnotetext{
${ }^{1}$ Doutorando(s) do Curso de Ciência Animal, UEL, Londrina, PR. E-mail: alexey_leon@yahoo.com.br; gfm@uel.br

${ }^{2}$ Profs. Drs. do Dept ${ }^{\circ}$ de Medicina Veterinária Preventiva, Universidade Estadual de Londrina, UEL, Londrina, PR. E-mail: jlgarcia@uel; jsgj@uel.br

* Autor para correspondência
} 


\section{Introdução}

A eimeriose ou coccidiose aviária, é uma parasitose intestinal que acomete diversas espécies de aves tendo como agente etiológico os protozoários do gênero Eimeria, sendo estes responsáveis por quadros de diarréia, perda de peso, elevada conversão alimentar, e, em alguns casos mais severos, alta taxa de mortalidade (YIN et al., 2011).

Apesar de potencialmente apresentar um quadro patológico severo, os quadros subclínicos são aqueles que mais causam problemas ao produtor por seu cunho econômico. Perdas devidas a eimeriose, na indústria avícola em 1995, foram estimadas em aproximadamente 40 milhões de libras esterlinas sobre uma produção de 625 milhões de frangos no Reino Unido. Nesta estimativa somente $17,5 \%$ destas perdas foram atribuídas à custos de profilaxia e tratamento, e cerca de $80 \%$ devido a perdas em conversão alimentar e ganho de peso (WILLIAMS, 1999). Segundo Luchese et al. (2007), atualmente, no Brasil, as perdas podem chegar aos US\$ 19 milhões/ ano. Este autor ainda afirma que as perdas podem chegar a US $\$ 1,5$ bilhão/ ano no mundo. Isto se dá em decorrência de uma série de fatores tais como: uso incorreto de anticoccídicos, diagnóstico incorreto da enfermidade e/ou espécies de Eimeria envolvidas, além da presença de cepas resistentes a determinadas drogas (CHAPMAN, 1994; ZULPO et al., 2007).

O uso indiscriminado de anticoccídicos tem resultado na seleção de cepas resistentes a drogas, as quais reduzem a eficácia de vários anticoccídicos em uso (CHAPMAN, 1997; COOMBS; MÜLLER, 2002; LI et al., 2004). Como em muitos países a legislação proíbe o uso destes produtos continuamente até o abate, períodos de retirada têm sido exigidos, os quais promovem aumento no risco de infecção no final do período de crescimento (VERMEULEN; SCHAAP; SCHETTERS, 2001). Diante da atual estratégia profilática, o Conselho da União Européia propôs a retirada progressiva dos anticoccídicos utilizados como aditivos na alimentação animal, até dezembro de 2012 (UNIÃO EUROPÉIA, 2003). Segundo a União Brasileira de Avicultura (UBABEF), o Brasil é o maior exportador do mundo de carne de frango. No ano de 2010 foram exportadas 3,8 milhões de toneladas, sendo $12,34 \%$ deste montante destinados a União Européia (UBABEF, 2010). Desta forma, existe uma necessidade de novos conceitos estratégicos para o controle da eimeriose aviária (VERMEULEN; SCHAAP; SCHETTERS, 2001).

Existe, atualmente, uma mudança comportamental da população consumidora, que busca e exige produtos que não apresentem resíduos de agentes químicos (VERMEULEN; SCHAAP; SCHETTERS 2001).

\section{Eimeria spp.}

Eimeria é um protozoário pertencente ao subfilo Apicomplexa, Família Eimeriidae, que apresenta várias espécies de interesse médico veterinário, podendo afetar mamíferos e aves. Sete espécies têm sido reconhecidas infectando galinhas: $E$. acervulina, E. maxima, E. tenella, E. brunetti, E. necatrix, E. mitis e E. praecox. Cada uma delas com características próprias em relação à prevalência, local de infecção, patogenicidade e imunogenicidade (GUIMARÃES JÚNIOR et al., 1991; CARDOZO; YAMAMURA, 2006; ZULPO et al., 2007). A E. tenella é uma das mais patogênicas das sete espécies que infectam galinhas, invadindo a mucosa cecal, causando inflamação e danos aos enterócitos (MIN et al., 2004).

Trata-se de parasito intracelular obrigatório que causa doença pela destruição das células em seu processo de replicação. Possuem duas etapas de multiplicação, uma assexuada (fase mais patogênica) e outra sexuada (KINNAIRD et al., 2004; CACHO et al., 2004). O ciclo de vida (Figura 1) é dividido em três fases: esporogonia (processo de esporulação dos oocistos, que ocorre no meio ambiente), merogonia (esquizogonia) 
e gametogonia (que ocorre no organismo do hospedeiro) (LILLEHOJ et al., 2000a). Os oocistos esporulados em material contaminado (cama, água, ração) são ingeridos pelos animais. A sua parede é destruída na moela por força mecânica, liberando os esporocistos que serão digeridos pelas enzimas digestivas, liberando a forma que invadirá a célula hospedeira: o esporozoíto. Dentro dos enterócitos, o esporozoíto sofre sucessivas divisões até a formação do meronte (esquizonte). Após a maturação este meronte rompe a célula liberando os merozoítos que invadem outras células repetindo o processo por 2 a 4 gerações, dependendo da espécie. Após esta fase, os merozoítos invadem novas células e diferenciam-se em micro e macrogametócitos, os quais irão se unir e formar o zigoto que dará origem ao oocisto, que é liberado no meio ambiente junto com as fezes. Este oocisto, sob condições ótimas de umidade, temperatura e oxigênio esporulam (entre 18 a 30 horas, dependendo da espécie), tornando-se infectantes. (KINNAIRD et al., 2004; CACHO et al., 2004).

Figura 1. Ciclo de vida de Eimeria spp. em frangos de corte.

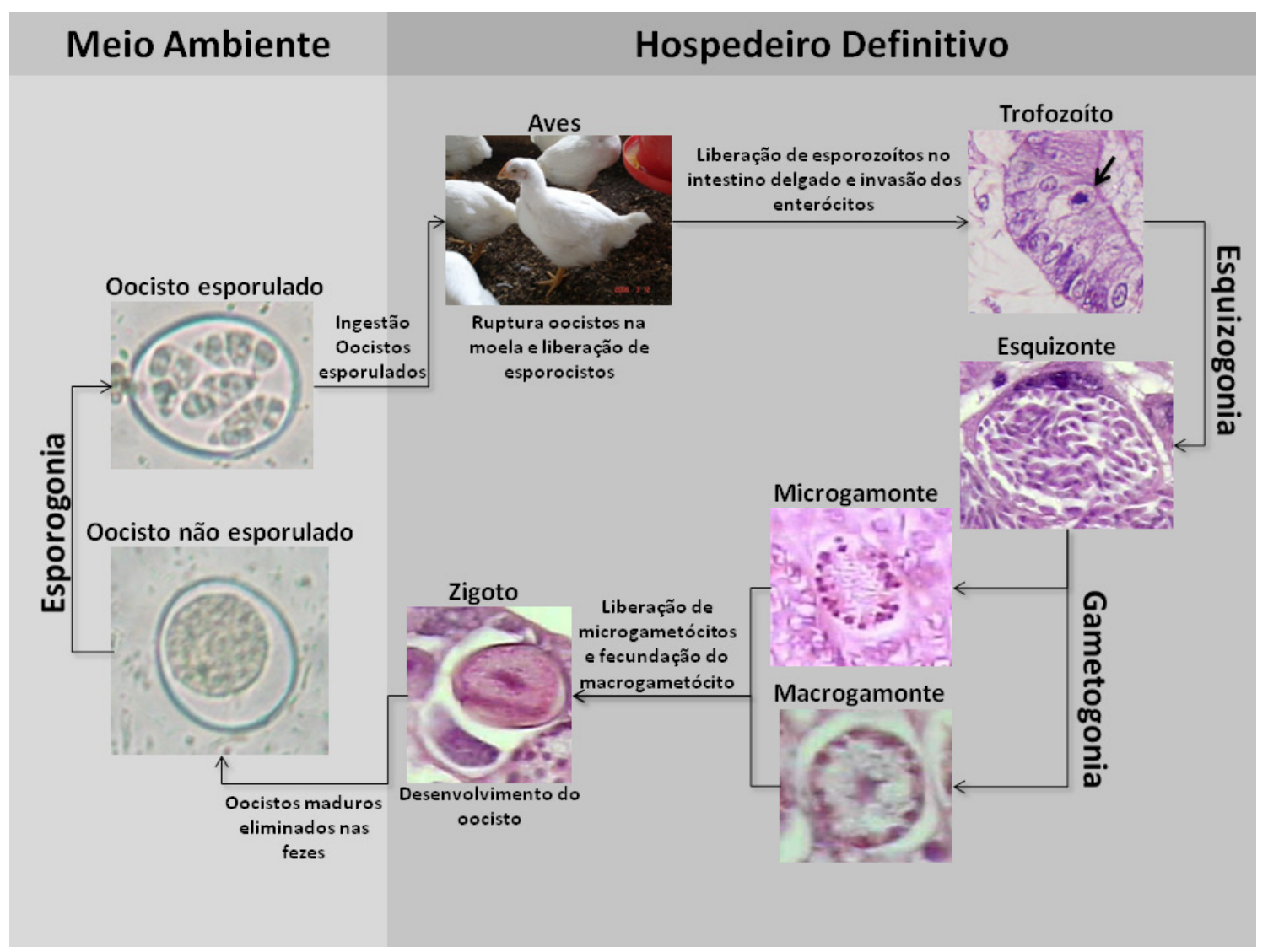

Fonte: Elaborado dos autores.

Aspectos imunológicos das aves e vacinas

Ainfecção por Eimeria induz uma resposta imune complexa e multifatorial no hospedeiro, embora esteja claro que muitas destas respostas não são essenciais na proteção contra desafio subseqüente
(SHIRLEY; SMITH; BLAKE, 2007). Devido a infecção ser confinada ao trato intestinal, o tecido linfóide associado ao intestino (GALT) exerce a primeira linha de defesa contra o agente tendo três funções principais, como o processamento e 
apresentação de antígenos, a produção de anticorpos intestinais (IgA), e a ativação da imunidade mediada por células (LILLEHOJ et al., 2000a).

Segundo Shirley, Smith e Blake (2007), a caracterização dos mecanismos imunes responsáveis pela proteção, tanto na infecção primária quanto na secundária, pela maioria das espécies de Eimeria, mostram o papel crítico das células $\mathrm{T}(\mathrm{CD} 4+)$, principalmente aquelas que expressam receptores $\alpha \beta$, e interferon gama (IFN- $\gamma$ ). Este último foi identificado em altas concentrações nas infecções por E. acervulina, E. maxima, e E. tenella. Ainda segundo estes autores, as células B e natural killer parecem exercer um papel menos importante na promoção de imunidade efetiva. Constantinoiu et al. (2011), reforçam a importância das células T na promoção de imunidade protetora na infecção de aves pelo gênero Eimeria.

Trout e Lillehoj (1996), descreveram que a resposta humoral não exerce um papel fundamental na proteção contra infecção, porém aponta para a importância da imunização materna e transferência de imunidade passiva.

A natureza exata dos mecanismos de defesa do hospedeiro frente a estes parasitos ainda permanece desconhecida, porém sabe-se que diversas proteínas, de diferentes organelas são importantes no processo de invasão celular e desenvolvimento da infecção, que poderiam estimular a resposta imune celular e prover proteção frente a infecção (KLOTZ, 2007). Devido a este fato, a utilização de vacinas atenuadas proporciona uma imunidade mais eficiente em comparação as vacinas de subunidades (mortas/ inativadas). Porém este tipo de vacina tem o inconveniente da possibilidade de manifestação clínica da doença (LILLEHOJ et al., 2000a). Assim, com o advento da biologia molecular, diversos estudos têm sido desenvolvidos nesta área, visando a estimulação específica de células promotoras de imunidade consistente (LAMPHEAR, et al., 2002).

A imunidade conferida pelas vacinas vivas de baixa dose e atenuadas é protetora, pois permite o desenvolvimento completo do ciclo do parasito e, conseqüentemente, estimula todas as vias da resposta imune, principalmente a resposta imune celular, a qual promove efetivamente a proteção contra infecções subseqüentes. Já a imunidade pelas vacinas recombinantes irá depender da proteína utilizada, sendo esta, de preferência, participante de etapas fundamentais no ciclo do parasito (LILLEHOJ et al., 2000a).

Os últimos 10 anos de pesquisa no desenvolvimento de uma vacina de subunidade contra diversos parasitos apicomplexos (Eimeria, Plasmodium, e Toxoplasma) revelaram a complexidade da relação parasito-hospedeiro, e indicam como caminho mais promissor o uso de antígenos recombinantes de proteínas de organelas específicas (presentes no complexo apical, como roptrias, micronemas e granulos densos) envolvidas no processo de invasão celular (JENKINS, 1998).

Existem diversos tipos de vacinas, porém somente vacinas vivas e atenuadas são comercializadas (exceção a vacina recombinante CoxAbic ${ }^{\circledR}$ ). Apesar disso, o seu uso ainda é discreto frente ao uso de anticoccidianos, possivelmente devido a sua menor eficácia e maior custo (DALTON; MULCAHY, 2001).

\section{Vacinas vivas}

As vacinas vivas atualmente utilizadas no controle da coccidiose aviária são as atenuadas ou as produzidas com cepas virulentas. A vantagem das atenuadas em relação as cepas virulentas, consiste na menor possibilidade de lesão intestinal, devido ao seu menor potencial reprodutivo e, ao mesmo tempo, conferindo maior imunidade aos animais (TOMASI, 2006).

As vacinas contendo cepas virulentas foram as primeiras utilizadas no controle da coccidiose, pois foi observado que o uso dessas cepas em uma sub-dose conferia imunidade protetora frente a um posterior desafio. Essas vacinas são utilizadas até 
hoje administradas de diferentes formas e veículos, sendo algumas através da água, outras em gel, através de spray, entre outros meios de aplicação. Existem diversas formas de se modular a patogenicidade destas cepas, como por meio da passagem em ovo embrionado, co-administração com anticoccídicos, baixa dose, entre outros. (LILLEHOJ et al., 2000a).

Segundo Lillehoj et al. (2000a), as cepas atenuadas são obtidas através de sucessivas passagens em ovos embrionados, seleção de cepas precoces e irradiação. Ainda segundo este autor, além destas três formas de atenuação, outras técnicas têm sido desenvolvidas, como a seleção de parasitas de diferentes locais do intestino e imunização com parasitos cultivados in vitro. No entanto estas técnicas mostraram ser menos eficientes que as técnicas de seleção de cepas precoces e as que sofreram irradiação.

Segundo Dalton e Mulcahy (2001), existem quatro vacinas atualmente no mercado, sendo duas delas vivas atenuadas (Paracox ${ }^{\circledR}$ e Livacox $®$ ) e duas com cepas virulentas (Coccivax ${ }^{\circledR}$ e Immunocox $\left.{ }^{\circledR}\right)$. As cepas atenuadas são obtidas após sucessivas passagens até obtenção de linhas precoces e pouco patogênicas (SHIRLEY; SMITH; BLAKE, 2007). Porém, apesar da promoção da imunidade, neste tipo de vacina, existe a possibilidade de reversão da atenuação e desenvolvimento de lesões mais intensas, que podem acarretar em perda de peso. Este tipo de vacina vem sendo mais utilizado na imunização de poedeiras e matrizes de reposição (DALTON; MULCAHY, 2001).

Além da reversão da atenuação, outro problema em relação as vacinas vivas está ligado ao mecanismo de infecção e o desenvolvimento da imunidade. Para que as aves desenvolvam imunidade protetora, os esporozoítos precisam invadir as células e realizar seu ciclo celular para que haja a estimulação do sistema imune celular (efetivamente protetor). Isso vale tanto para a infecção natural quanto para as vacinas atenuadas. Então, para que as vacinas surtam o efeito desejado, os parasitos precisam invadir as células intestinais e realizar seu ciclo. Levando este fato em consideração, é notório que o uso de coccidiostáticos (que impedem o ciclo destes parasitos), interferiria no desenvolvimento da imunidade. Então, quando se usa este tipo de vacinas, não se deve utilizar em conjunto com estas drogas, caso contrário ocorrerá uma maior suscetibilidade destes animais caso se tornem infectados com cepas naturais.

\section{Vacinas inativadas}

Esta classe de vacina envolve as vacinas de organismos mortos ou inativados e antígenos de superfície (LILLEHOJ et al., 2000a).

Nestas vacinas são usados fragmentos de Eimeria spp, principalmente esporozoítos (por ser a forma infectante), ou mesmo fragmentos de oocistos. Porém, o uso deste tipo de vacina tem a característica de estimular uma resposta imune humoral, a qual não exerceria uma proteção tão satisfatória quanto à resposta celular (TIZARD, 2002). Em contrapartida, Garcia et al. (2008), demonstraram uma diminuição nos escores de lesão, eliminação de oocistos e lesão tecidual utilizando uma vacina com subunidades de esporozoítos administrada por via nasal.

\section{Vacinas de proteinas e DNA recombinantes}

Há cerca de duas décadas diversos laboratórios concentraram esforços no desenvolvimento de uma vacina contra coccidiose aviária utilizando antígenos recombinantes de diferentes estágios de desenvolvimento (esporozoítos, merozoítos, gametócitos) de Eimeria spp. Essas seqüências de DNA são expressas em uma variedade de vetores eucarióticos e procarióticos (JENKINS, 2001). Segundo Shirley, Smith e Blake. (2007), a utilização de antígenos para confecção de vacinas, deve utilizar um veículo, que pode ser um vetor vivo, um DNA recombinante, ou mesmo uma proteína expressa e purificada. 
A identificação dos estágios do ciclo de vida do parasita é o passo mais importante na escolha das proteínas a serem utilizadas na confecção de uma vacina recombinante. Os esporozoítos são preferidos pela facilidade de obtenção e por estarem envolvidos diretamente no processo de invasão celular (LILLEHOJ et al., 2000a). A escolha da proteína a ser utilizada ainda depende de alguns fatores, como a tecnologia para produção em escala, a imunogenicidade do produto recombinante e modificações pós-translacionais (ex. glicosilação) (FERNÁNDEZ-ROBLEDO et al., 2010).

Boghal et al. (1992) induziram proteção parcial em frangos jovens utilizando proteína recombinante de E. tenella e E. acervulina experimentalmente infectados. Os autores descreveram ainda estimulo da imunidade celular e um grau razoável de proteção nos animais. Este trabalho foi a primeira descrição de pintos de um dia de idade vacinados com proteínas recombinantes.

Atualmente, existe apenas uma vacina comercial com proteínas recombinantes para o controle da coccidiose aviária, a CoxAbic ${ }^{\circledR}$. Esta vacina consiste de proteínas recombinantes obtidas de gametócitos de Eimeria máxima. Os genes gam56 e gam82 foram clonados (pTRCHisB), e suas proteínas expressas em vetor biológico (E. coli TOP10), e, posteriormente, purificadas (BELLI et al., 2004).

As possibilidades na confecção de vacinas cresceram com o uso de banco de dados de proteínas na internet (GeneBank). Klotz et al. (2005) identificaram proteínas (secretórias e de superfície) já reconhecidas de outros parasitos Apicomplexa como possíveis candidatas a vacinas devido sua homologia com Eimeria tenella.

\section{Proteinas intracelulares secretórias e estruturais}

Os antígenos intracelulares de Eimeria desempenham importantes papéis na relação parasito-hospedeiro e no ciclo de vida do parasito, sendo assim, são considerados melhores candidatos a confecção de vacinas, por bloquearem as atividades relacionadas ao processo de invasão celular. Entre estes, estão os componentes dos corpos refratários e organelas do complexo apical (LILLEHOJ et al., 2000a).

Aparentemente, diversas proteínas associadas ao complexo apical estão envolvidas no processo de invasão celular e formação do vacúolo parasitóforo. A clonagem de genes que codificam as proteínas associadas às roptrias, micronemas $\mathrm{e}$ grânulos densos forneceu informações de eventos que ocorrem durante e após a invasão celular (JENKINS, 1998). Proteínas de micronema têm sido utilizadas na confecção de vacinas recombinantes, como a EtMIC2 (DALLOUL et al., 2005) e EtMIC1 (SUBRAMANIAN et al., 2008). Alguns autores utilizaram partes de regiões consideradas imunogênicas de algumas proteínas, como o antígeno 5401 da região C-terminal da proteína de micronema EtMIC4 (DANFORTH et al., 1989; DU; HU; WANG, 2005).

Outra organela presente no complexo apical são as roptrias. Esta organela, localizada na região anterior do complexo apical, possui um compartimento com um repertório distinto de proteínas envolvidas diretamente na invasão da célula hospedeira (PROELLOCKS; COPPEL; WALLER, 2010). No entanto, apesar da sua importância neste evento, não existem muitos estudos utilizando proteínas desta organela na imunização de aves, com exceção da proteína EAMZp30-47, obtida de merozoítos de Eimeria acervulina, a qual evidenciou o estímulo das células T de aves (JENKINS et al., 1990).

Os corpos refratários são estruturas específicas dos parasitos da família Eimeriidae, desprovidos de membrana. Apesar de terem sido estudados anteriormente e detectados nos estágios sexuais precoces (de esporozoíto à esquizonte de primeira geração), suas funções permanecem desconhecidas (VENEVELLES et al., 2006). Uma proteína de corpo refratário de E. tenella (Etp28) foi clonada e expressa em grande quantidade em sistema 
de expressão por Bacullovirus (YANG et al., 1998), sendo, esta descrita pelos autores como imunoprotetora e candidata a vacina para combater a coccidiose aviária. Outro antígeno de corpo refratário, SO7, derivado de gene homônimo, também tem sido estudado na confecção de vacinas (POGONKA, et al., 2003; YANG et al., 2010).

Além disso, outras proteínas, a princípio estruturais e com outras funções, têm sido reconhecidas no processo de invasão celular, como as proteínas de choque térmico HSP70 (CACHO et al., 2008) e HSP90 (DASZAK, 1999; PÉROVAL; PERY; LABBE, 2006), mostrando-se possíveis candidatas a estudos futuros.

Proteínas superficiais estruturais

Os antígenos de superfície são importantes na confecção de vacinas por desempenharem um papel direto na interação parasito-hospedeiro, e resultados promissores foram observados utilizando antígenos superfície (membrana celular) nativos e recombinantes (LILLEHOJ et al., 2000a).

Estas proteínas de membrana são obtidas, preferencialmente, de esporozoítos ou merozoítos, por serem as formas infectantes do parasito. São amplificadas de genes, como cSZ-1 (esporozoíto) e cMZ-8 (merozoíto), e tem a propriedade de estimularem a imunidade humoral e celular in vitro (JENKINS; LILLEHOJ; DAME, 1988). Li et al. (2010), em um trabalho mais recente, verificou uma significativa diminuição em lesões intestinais, perda de peso e eliminação de oocistos em infecção experimental por E. tenella, imunizando aves com uma proteína (cSZ-2) de E. acervulina. Shah et al. (2010), utilizando a mesma proteína e sob as mesmas condições, observaram resultados semelhantes.

Recentemente outra proteína vem sendo utilizada em estudos para imunógenos, a proteína 3-1E, presente na superfície de esporozoítos e esquizontes de Eimeria acervulina, e que demonstrou ser altamente imunogênica, produzindo proteção imune parcial contra a coccidiose (MA, et al., 2011). Assim como a proteína $3-1 \mathrm{E}$, outra proteína também de superfície tem sido amplamente utilizada em testes vacinais, a proteína TA4, também conhecida como SAG1. Esta proteína obtida de E. acervulina ou de E. tenella, mostrou ser eficiente na promoção de imunidade protetora a coccidiose, quando submetidas a desafios homólogo e heterólogo, associadas a interleucinas e outras citocinas como compostos adjuvantes (LILLEHOJ et al., 2000b; MIN et al., 2002; XU et al., 2008; SONG et al., 2009).

Em outro estudo, Geriletu e Xurihua (2011), obtiveram resultados satisfatórios imunizando aves com uma proteína de superfície de merozoíto, denominada MZ5-7, associada a uma interleucina IL-17 de frangos.

\section{DNA recombinante}

Vacinas de DNA utilizam genes que codificam proteínas imunogênicas de patógenos (gene de interesse carreado por vetor biológico, como plasmídio bacteriano ou DNA viral) ao invés das proteínas já expressadas. Elas são utilizadas em conjunto com elementos regulatórios apropriados como os promotores e os estimuladores, permitindo que a proteína codificada seja expressa e, assim, ser reconhecida pelo sistema imune do hospedeiro de uma forma que simule a infecção natural. Este tipo de vacina requer a transferência de genes e expressão do antígeno em tecidos acessíveis ao sistema imunológico, como pele, músculo e mucosas (LILLEHOJ et al., 2000a).

Este tipo de vacina pode ser confeccionada utilizando somente plasmídio clonado (MIN et al., 2002; XU et al., 2008; SONG et al., 2009; SHAH et al., 2010) ou um vetor biológico portando o gene que codifica a proteína desejada (YANG et al., 2010), ou mesmo, a proteína expressada.

\section{Adjuvantes}

Os adjuvantes são utilizados com intuito de aumentar a resposta imune das vacinas, e também 
em imunologia experimental. A existência de efeitos adjuvantes foi descrito pela primeira vez por Glenny et al. 1926. A natureza química, modo de ação e efeitos colaterais dos adjuvantes são altamente variáveis. Alguns efeitos colaterais podem ser atribuídos à estimulação de diferentes mecanismos do sistema imune que podem refletir em reações farmacológicas adversas (BRUNNER; JENSEN-JAROLIN; PALI-SCHÖLL, 2010).

Os adjuvantes mais comuns são o hidróxido de alumínio, fosfato de alumínio e fosfato de cálcio, além de emulsões de óleos, produtos bacterianos e seus derivados sintéticos, como lipossomos. Atualmente adjuvantes como MPL (lipídio monofosforil A), ISCOMs associados a Quil-A e SAF (Syntex adjuvant formulation) contendo treonil derivado do dipeptídeo muramil tem sido utilizados em vacinas. A escolha de um composto adjuvante irá depender de um equilíbrio entre a sua imunogenicidade e baixos, ou aceitáveis, efeitos colaterais (GUPTA et al., 1993).

A escolha do adjuvante depende de algumas considerações, como conhecimento da patogênese da doença e da proteção correlata, metas da vacina, antígenos envolvidos, população envolvida, e o conhecimento do modo de ação do adjuvante. Intensificar os esforços para compreender o modo de ação dos adjuvantes é uma parte fundamental do processo (MASTELIC et al., 2010).

\section{Conclusão}

O uso de anticoccidianos na ração de frangos ao longo dos anos permitiu a seleção de cepas resistentes de Eimeria spp. Tal quadro desestimulou a produção de novos medicamentos pelos laboratórios. A possibilidade de resíduos na carne e a exigência do mercado consumidor foram outros fatores determinantes. Com isso a Comissão da União Européia determinou a retirada gradativa desses agentes da ração de frangos até dezembro de 2012. Diante de tal fato, houve o estímulo de pesquisas por uma forma alternativa de controle, no caso as vacinas.

Já existem alguns tipos de vacinas no mercado, principalmente as vivas virulentas e atenuadas. Essas vacinas, apesar de serem eficientes na promoção de imunidade protetora, ainda possuem desvantagens (como o custo elevado e possibilidade de causar doença) que não permitiram a total aceitação por parte dos produtores.

Diante de tal fato as vacinas recombinantes parecem ser, atualmente, a alternativa mais promissora no controle da coccidiose. Entretanto, para que estas vacinas sejam efetivas, alguns fatores devem ser levados em consideração, como as escolhas das proteínas, adjuvantes e vias de administração corretas. Apesar de existirem diversas pesquisas com este tipo de vacina, só existe uma vacina comercializada atualmente $\left(\mathrm{CoxAbic}^{\circledR}\right)$.

Finalmente, é importante ressaltar que o controle da coccidiose aviária é extremamente complexo, e que, novos estudos devem ser estimulados para o desenvolvimento de métodos eficazes para a produção de carne de frango livre de medicamentos.

\section{Referências}

BELLI, A. I.; MAI, K.; SKENE, C. D.; GLEESON, M. T.; WITCOMBE, D. M.; KATRIB, M.; FINGER, A.; WALLACH, M. G.; SMITH, N. C. Characterization of the antigenic and immunogenic properties of bacterially expressed, sexual stage antigens of the coccidian parasite, Eimeria maxima. Vaccine, Kidlinton, v. 22, n. 31-32, p. 4316-4325, 2004.

BRUNNER, R.; JENSEN-JAROLIN, E.; PALISCHÖLL, I. The ABC of clinical and experimental adjuvants - a brief overview. Immunology Letters, v. 128, n. 1, p. 29-35, 2010.

CACHO, E.; GALlEGO, M.; PAGES, M.; MONTEAGUDO, L.; SÁNCHEZ-ACEDO, C. HSP70 is a part of the synaptonemal complex in Eimeria tenella. Parasitology International, v. 57, p. 454-459, 2008.

CACHO, E.; GALLEGO, M.; LÓPEZ-BERNARD, F.; QUÍLEZ, J.; SÁNCHEZ-ACEDO, C. Expression of anti-apoptotic factors in cells parasitized by secondgeneration schizonts of Eimeria tenella and Eimeria 
necatrix. Veterinary Parasitology, Amsterdam, v. 45, n. 3-4, p. 287-300, 2004.

CARDOZO, S. P.; YAMAMURA, M. H. Identificação de espécies de Eimeria $s p$. E avaliação de escore de lesões intestinais entre frangos vacinados e tratados com anticoccidianos, produzidos no sistema colonial/caipira. Semina: Ciências Agrárias, Londrina, v. 27, n. 2, p. 261270, abr/.jun. 2006.

CHAPMAN, H. D. Situação atual da coccidiose nos EUA. In: SIMPÓSIO INTERNACIONAL SOBRE COCCIDIOSE, 7., 1994, Santos. Anais... Santos: FACTA, p. 55-62, 1994.

Biochemical, genetic and applied aspects of drug resistance in Eimeria parasites of the fowl. Avian Pathology, v. 26, n. 2, p. 221-224, 1997.

CONSTANTINOIU, C. C.; MOLlOy, J. B.; JORGENSEN, W. K.; COLEMAN, G. T. Characterization of the antibody responses in birds following infection with wild-type and attenuated strains of Eimeria tenella and Eimeria necatrix. Veterinary Parasitology, Amsterdam, v. 175, n. 1-2, p. 47-51, 2011.

COOMBS, G. H.; MÜLLER, S. Recents advances in the search for new anti-coccidial drugs. International Journal for Parasitology, Elmsford, v. 32, n. 5, p. 497508, 2002.

DALTON, J. P.; MULCAHY, G. Parasites vaccines - a reality? Veterinary Parasitology, Amsterdam, v. 98, n. 1-3, p. 149-167, 2001.

DALLOUL, R. A.; LILLEHOJ, H. S.; KLINMAN, D. M.; DING, X.; MIN, W.; HECKERT, R. A.; LILLEHOJ, E. P. In ovo administration of $\mathrm{CpG}$ oligodeoxynucleotides and the recombinant microneme protein $\mathrm{MIC} 2$ protects against Eimeria infections. Vaccine, Kidlinton, v. 23, n. 24, p. 3108-3113, 2005.

DANFORTH, H. D.; AUGUSTINE, P. C.; RUFF, M. D.; MCCANDLISS, R.; STRAUSBERG, R. L.; LIKEL, M. Genetically engineered antigen confers partial protection against avian coccidial parasites. Poultry Science, Honduras, v. 68, n. 12, p. 1643-52, 1989.

DASZAK, P. Zoite migration during infection: parasite adaptation to host defences. Parasitology Today, Califórnia, v. 15, n. 2, p. 67-72, 1999.

DU,A.; HU, S.; WANG, S. Eimeria tenella: Ginsenosidesenhanced immune response to the immunization with recombinant 5401 antigen in chickens. Experimental Parasitology, v. 111, n. 3, p. 191-197, 2005.

FERNÁNDEZ-ROBLEDO, J. A.; VASTA, G. R. Production of recombinant proteins from protozoan parasites. Trends in Parasitology, v. 26, n. 5, p. 244-254, 2010.

GARCIA, J. L.; GUIMARÃES JUNIOR, J. S.; BOGADO, A. L. G.; BUNGNI, F. M.; RAMALHO, D. C.; SOUZA, L. M. Eimeria tenella: utilization of a nasal vaccine with sporozoite antigens incorporated into iscom as protection for broilers breeders against a homologous challenge. Experimental Parasitology, v. 120, n. 2, p. 185-190, 2008.

GERILETU, XU, L.; XURIHUA, LI, X. Vaccination of chickens with DNA vaccine expressing Eimeria tenella MZ5-7 against coccidiosis. Veterinary Parasitology, Amsterdam, v. 177, n. 1-2, p. 6-12, 2011.

GLENNY, E. T.; POPE, C. G.; WADDINGTON, H.; WALLACE, U. Immunological notes XVII to XXIV. $J$. Pathol., v. 29, n. 1, p. 31-40, 1926.

GUIMARÃES JÚNIOR, J. S.; GUIMARÃES, I. G.; PEREIRA, A. B. L.; ROCHA, M. A.; CARDOSO, M. A.; OIDE, M. M.; TANAKA, A. A.; RORATO, A. A. Ocorrência de Eimeria spp em galinhas reprodutoras no norte do Paraná. Semina: Ciências Agrárias, Londrina, v. 12, n. 1, p. 44-48, 1991.

GUPTA, R. K.; RELYVELD, E. H.; LINDBLAD, E. B.; BIZZINI, B.; BEN-EFRAIN, S.; GUPTA, C. K. Adjuvants - a balance between toxicity and adjuvanticy. Vaccine, Kidlinton, v. 11, n. 3, p. 293-306, 1993.

JENKINS, M. C. Advances and prospects for subunit vaccines against protozoa of veterinary importance. Veterinary Parasitology, Amsterdam, v. 101, n. 3-4, p. 291-310, 2001.

- Progress on developing a recombinant coccidiosis vaccine. International Journal for Parasitology, Elmsford, v. 28, n. 7, p. 1111-1119, 1998.

JENKINS, M. C.; LILLEHOJ, H. S.; DAME, J. B. Eimeria acervulina: DNA cloning and characterization of recombinant sporozoite and merozoite antigens. Experimental Parasitology, v. 66, n. 1, p. 96-107, 1988.

JENKINS, M. C.; LILLHOJ, H. S.; BARTA, J. R.; DANFORTH, H. D.; STROHLCIN, D. A. Eimeria acervulina: cloning a cDNA encoding an immunogenic region of several related merozoite surface and rhoptry neck proteins. Experimental Parasitology, v. 70, n. 3, p. 353-362, 1990 .

KINNAIRD, J. H.; BUMSTEAD, A. M.; MANN, D. J.; RYAN, R.; SHIRLEY, M. W.; SHIELS, B. R.; TOMLEY, F. M. EtCRK2, a cyclin-dependent kinase gene expressed during the sexual and asexual phases of the Eimeria tenella life cycle. International Journal for Parasitology, Elmsford, v. 34, n. 6, p. 683-692, 2004. 
KLOTZ, C. Identification of Eimeria tenella genes encoding for secretory proteins and evaluation of candidates by DNA immunization studies in chickens. Vaccine, Kidlinton, v. 25, n. 36, p. 6625-6634, 2007.

KLOTZ, C.; MARHÖFER, R. J.; SELZER, P. M.; LUCIUS, R.; POGONKA, T. Eimeria tenella: Identification of secretory and surface proteins from expressed sequence tags. Experimental Parasitology, v. 111, n. 1, p. 14-23, 2005.

LAMPHEAR, B. J.; STREATFIELD, S. J.; JILKA, J. M.; BROOKS, C. A.; BARKER, D. K.; TURNER, D. D.; DELANEY, D. E.; GARCIA, M.; WIGGINS, B.; WOODARD, S. L.; HOOD, E. E.; TIZARD, I. R.; LAWHORN, B.; HOWARD, J. A. Delivery of subunit vaccines in maize seed. Journal of Controlled Release, $\mathrm{v}$. 85, n. 1-3, p. 169-180, 2002.

LI, G. Q.; KANU, S.; XIANG, F. Y.; XIAO, L. Z.; CHEN, H. W.; YE, H. J. Isolation and selection of ionophoretolerant Eimeria precocious lines: E. tenella, E. maxima and E. acervulina. Veterinary Parasitology, Amsterdam, v. 119, n. 4, p. 261-276, 2004.

LI, X.; SHAH, M. A. A.; YAN, R.; XU, L.; SONG, X. A recombinant DNA vaccine encoding Eimeria acervulina cSZ-2 induces immunity against experimental $E$, tenella infection. Veterinary Parasitology, Amsterdam, v. 169, n. 1-2, p. 185-189, 2010.

LILLEHOJ, E. P.; YUN, C. H.; LILLEHOJ, H. S. Vaccines against the avian enteropathogens Eimeria, Cryptosporidium and Salmonella. Animal Health Research Reviews, v. 1, n. 1, p. 47-65, 2000a.

LILLEHOJ, H. S.; CHOI, K. D.; JENKINS, M. C.; VAKHARIA, V. N.; SONG, K. D.; HAN, J. Y.; LILLEHOJ, E. P. A recombinant Eimeria protein inducing interferon- $\gamma$ production: comparison of different gene expression systems and immunization strategies for vaccination against coccidiosis. Avian Diseases, v. 44, n. 2, p. 379-389, 2000b.

LUCHESE, F. C.; PERIN, M.; AITA, R. S.; MOTTIN, V. D.; MOLENTO, M. B.; MONTEIRO, S. G. Prevalência de espécies de Eimeria em frangos de criação industrial e alternativa. Brazilian Journal of Veterinary Research and Animal Science, São Paulo, v. 44, n. 2, p. 81-86, 2007.

MA, D.; MA, C.; PAN, L.; LI, G.; YANG, J.; HONG, J.; CAI, H.; REN, X. Vaccination of chickens with DNA vaccine encoding Eimeria acervulina 3-1E and chicken IL-15 offers protection against homologous challenge. Experimental Parasitology, v. 127, n. 1, p. 208-214, 2011.
MASTELIC, B.; AHMED, S.; EGAN, W. M.; GIUDICE, G.; GOLDING, H.; GUST, I.; NEELS, P.; REED, S. G.; SHEETS, R. L.; SIEGRIST, C.; LAMBERT, P. Mode of action of adjuvants: implications for vaccine safety and design. Biologicals, v. 38, n. 5, p. 594-601, 2010.

MIN, W.; DALlOUL, R. A.; LILLEHOJ, H. S. Application of biotechnological tools for coccidia vaccine development. Journal of Veterinary Science, v. 5, n. 4, p. 279-288, 2004.

MIN, W.; LILLEHOJ, H. S.; BURNSIDE, J.; WEINING, K. C.; STAEHELI, P.; ZHU, J. J. Adjuvant effects of $I L-1 \beta, I L-2, I L-8, I L-15, I F N-\alpha, I F N-\gamma, T G F-\beta 4$ and lymphotactin on DNA vaccination against Eimeria acervulina. Vaccine, Kidlinton, v. 20, n. 1-2, p. 267-274, 2002.

PÉROVAL, M.; PERY, P.; LABBE, M. The heat shock protein 90 of Eimeria tenella is essential for invasion of host cell and schizont growth. International Journal for Parasitology, Elmsford, v. 36, n. 10-11, p. 1205-1215, 2006.

POGONKA, T.; KLOTZ, C.; KOVACS, F.; LUCIUS, R. A single dose of recombinant Salmonella typhimurium induces specific humoral immune responses against heterologous Eimeria tenella antigens in chickens. International Journal for Parasitology, Elmsford, v. 33, n. 1, p. 81-88, 2003.

PROELLOCKS, N. I.; COPPEL, R. L.; WALLER, K. L. Dissecting the apicomplexan rhoptry neck proteins. Trends in Parasitology, v. 26, n. 6, p. 297-304, 2010.

SHAH, M. A. A.; YAN, R.; XU, L.; SONG, X. LI, X. A recombinant DNA vaccine encoding Eimeria acervulina cSZ-2 induces immunity against experimental E. tenella infection. Veterinary Parasitology, Amsterdam, v.169, n. 1-2, p. 185-189, 2010.

SHIRLEY, M. W.; SMITH, A. L.; BLAKE, D. P. Chalenges in the successful control of the avian coccidia. Vaccine, Kidlinton, v. 25, n. 30, p. 5540-5547, 2007.

SONG, X.; XU, L.; YAN, R.; HUANG, X.; SHAH, M. A. A.; LI, X. The optimal immunization procedure of DNA vaccine pcDNA-TA4-IL-2 of Eimeria tenella and its cross-immunity to Eimeria necatrix and Eimeria acervulina. Veterinary Parasitology, Amsterdam, v. 159, n. 1, p. 30-36, 2009.

SUBRAMANIAN, B. M.; SRIRAMAN, R.; RAO, N.; RAGHUL, J.; THIAGARAJAN, D.; SRINIVASAN. Cloning, expression and evaluation of the efficacy of a recombinant Eimeria tenella sporozoite antigen in birds. Vaccine, Kidlinton, v. 26, n. 27-28, p. 3483-3496, 2008.

TIZARD, I. R. The avian antibody response. Seminars in Avian and Exotic Pet Medicine, v. 11, n. 1, p. 2-14, 2002. 
TOMASI, P. H. D. Avaliação de vacinas contra a coccidiose e a utilização de peptídeos em frangos de corte. 2006. Dissertação (Mestrado em Ciências Veterinárias) - Universidade Federal do Paraná, Curitiba.

TROUT, J. M.; LILLEHOJ, H. S. T. Lymphocyte roles during Eimeria acervulina and Eimeria tenella infections. Veterinary Immunology and Immunopathology, v. 53, n. 1-2, p. 163-172, 1996.

UNIÃO BRASILEIRA DE AVICULTURA UBABEF. Avicultura brasileira em 2010: exportações e produção. 2010. Disponível em: <http://www.abef. com.br/noticias_portal/down.php?arq=RXN0YXRpc3R pY2FzX1ViYWJIZ18yMDEwX0ZpbmFsLmRvYw=>. Acesso em: 09 jan. 2012.

UNIÃO EUROPÉIA. Parlamento Europeu e Conselho. Regulamento (CE) n. 1831, de 22 de Setembro de 2003. Relativoaosaditivosdestinadosàalimentaçãoanimal.Lex: Jornal Oficial da União Européia, [Documento on line]. Disponível em: <http://eur-lex.europa.eu/LexUriServ/ site/pt/oj/2003/1_268/1_26820031018pt00290043.pdf>. Acesso em: 19 abr. $200 \overline{7}$.

VENEVELLES, P.; CHIC, J. F.; FAIGLE, W.; LOMBARD, B.; LOEW, D.; PÉRY, P.; LABBÉ, M. Study of proteins associated with the Eimeria tenella refractile body by a proteomic approach. International Journal of Parasitology, Elmsford, v. 36, n. 13, p. 13991407, 2006.

VERMEULEN, A. N.; SCHAAP, D. C.; SCHETTERS, T. H. P. M. Control of coccidiosis in chickens by vaccination. Veterinary Parasitology, Amsterdam, v. 100, n. 1-2, p. 13-20, 2001.

WILLIAMS, R. B. A compartmentalized model for the estimation of the cost of coccidiosis to the world's chicken production industry. International Journal for Parasitology, Elmsford, v. 29, n. 8, p. 1209-1229, 1999.
XU, Q.; SONG, X.; XU, L.; YAN, R.; SHAH, M. A. A.; LI, X. Vaccination of chickens with a chimeric DNA vaccine encoding Eimeria tenella TA4 and chicken IL-2 induces protective immunity against coccidiosis. Veterinary Parasitology, Amsterdam, v. 156, n. 3-4, p. 319-323, 2008.

YANG, G.; WANG, C.; HAO, F.; ZHANG, Y.; LI, Y. Studies on construction of a recombinant Eimeria tenella SO7 gene expressing Escherichia coli and its protective efficacy against homologous infection. Parasitology International, v. 59, n. 4, p. 517-523, 2010.

YANG, L.; ZHU, W.; WANG, X. Z.; LONG, Q. X.; XIE, M. Q.; HUANG, X. Q. Cloning of Etp28 gene of Eimeria tenella (Guangdong strain) sporozoites and its expression in bacullovirus expression system. Sheng wu hua xue yu sheng wu wu li xue bao Acta biochimica et biofhysica Sinica. Shangai Institute of Biochemistry, Academia Sinica, v. 30, n. 3, p. 293-298, 1998.

YIN, G.; LIU, X.; ZOU, J.; HUANG, X.; SUO, X. Coexpression of reporter genes in the widespread pathogen Eimeria tenella using a double-cassette expression vector strategy. International Journal for Parasitology, Elmsford, v. 41, n. 8, p. 813-816, 2011.

ZULPO, D.; PERETTI, J.; ONO, L. M.; LONGHI, E.; OLIVEIRA; M. R.; GUIMARÃES, I. G.; HEADLEY, S. A.; GUIMARÃES JUNIOR, J. da S.; GARCIA, J. L. Patogenicidade e observações histopatológicas de frangos de corte infectados experimentalmente com isolados de Eimeria tenella, E. acervulina e E. máxima. Semina: Ciências Agrárias, Londrina, v. 28, n. 1, p. 97104, jan./mar. 2007. 
